\title{
Recent Advances in Fixation and Hydrogenation of Carbon Dioxide
}

\author{
Di Wu, Daoping He, Guodong Yao and Fangming Jin ${ }^{\star}$
}

\begin{abstract}
School of Environmental Science and Engineering, State Key Lab of Metal Matrix Composites, Shanghai Jiao Tong University, 800 Dongchuan RD, Shanghai, 200240, China
\end{abstract}

Tel/Fax: 86-21-54742283; E-mail: fmjin@sjtu.edu.cn

\section{Keywords: Carbon dioxide; Hydrocarbon; Hydrothermal reaction; Energy conversion}

\begin{abstract}
The combustion of organics and fossil fuel have led to higher greenhouse gas carbon dioxide production and making global warming a pressing issue. Conversion of carbon dioxide into value-added chemicals and fuels is regarded as a more attractive and promising way from the viewpoints of reducing carbon dioxide emission by utilizing it as a feedstock and storing renewable energy in the form of high energy density fuels. In this paper, we reviewed the current progress of carbon dioxide fixation and transformation methods.
\end{abstract}

\section{Introduction}

In the natural carbon cycle, the recycling of carbon dioxide mainly depends on the photosynthesis of plants and the absorption of carbon dioxide by the ocean. However, with the large-scale felling of trees, the ability of nature to deal with carbon dioxide has become weaker and weaker. On the other hand, the use of fossil fuel and combustion to obtain energy released a large amount of carbon dioxide, which led to a serious imbalance in the earth's carbon cycle. Human emissions of carbon dioxide have even exceeded the rate of carbon sequestration in nature. From the point of view of the distribution of global energy use, most of the current research on renewable energy such as wind power and solar energy and a series of new forms of local energy utilization still can not meet the needs of human society. Therefore, human is now facing the most severe challenge. At present, there are two main methods for effectively treating and reducing the concentration of carbon dioxide: capture and storage of carbon dioxide (CCS) and conversion of carbon dioxide (CCU) [1].

\section{Carbon Capture and Storage (CCS)}

Carbon dioxide capture and storage (CCS) refers to the process of separating carbon dioxide from industrial sources of production or sources of related energy, transporting it to a fixed storage location, and permanently isolating it from the atmosphere. Through this process, carbon dioxide gas will be compressed, transported and enclosed in geological rock formations, marine areas, extensive carbonate ores, or for industrial processes. This method is relatively simple, but the operation is complicated. Carbon dioxide capture and storage technologies include capture and storage [2,3].

Carbon dioxide capture technologies can be divided into Post-combustion capture, Pre-combustion capture and Oxy-combustion (Fig. 1). In post-combustion capture, carbon dioxide is separated from the flue gases that were originally present in the air or subsequently generated by combustion. Carbon is removed prior to combustion of the fuel during pre-combustion capture. In oxy-combustion capture, the process is in pure oxygen. The concentration of carbon dioxide in the gas stream, the pressure of the gas stream and the type of fuel (solid or gas) are the most important factors to be considered when selecting the capture system correctly.

The carbon dioxide sequestration technology is mainly geologic sequestration (in alkaline blocks, oil and gas fields, inaccessible coal fields and deep salt marsh formations), marine sequestration (usually directly into the sea or seafloor) and carbon dioxide solidification into inorganic component carbonate (storage in mineral). 

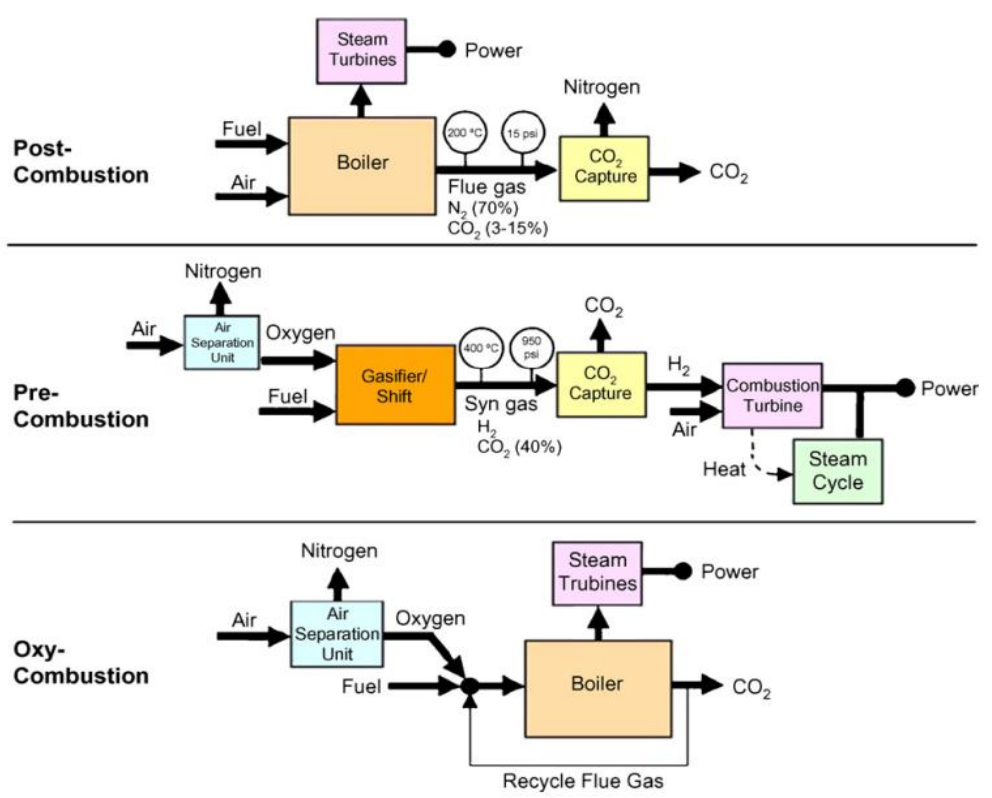

Fig. 1. Scheme of post-combustion, pre-combustion, and oxy-combustion systems[2].

At present, the research on carbon dioxide capture and storage technology is still in its infancy. Although some demonstration projects have already started to operate, there is still a long way to go before large-scale practical application. There are two broad categories of potential risks associated with massive carbon dioxide leaks in the crustal reservoir: global and local risks. The global risk posed by the release of carbon dioxide means that carbon dioxide gas can cause serious climate changes if most of the carbon dioxide gas in the sealed structure leaks into the atmosphere. However, there may be two types of localized risks in the event of a possible leak. Atmospheric carbon dioxide concentrations of more than 7-10\% will immediately endanger people's lives and health. Under such circumstances, the main object affected by the disaster is the aquifer and ecosystems. For marine storage, injecting billions of tons of carbon dioxide will result in measurable changes in the composition of the ocean's chemical composition. According to the study, the increase of carbon dioxide in the ocean may affect the efficiency, multiplication and growth of aquatic calcification, resulting in the periodic oxygen supply and the greatly increased mortality rate. Therefore, carbon dioxide, as a stable carbon-containing compound, can be used as a rich and cheap source of carbon to synthesize organic compounds to increase its value [3].

\section{Carbon dioxide reduction and conversion}

In addition to being stored as a waste stream, carbon dioxide captured can be used as a stable source of carbon to produce high value-added products such as methane, methanol and ethanol that can be reused not only to reduce carbon dioxide in the atmosphere but also to provide human beings with high-quality energy that can be used. From the late nineteenth century to the early twentieth century, research on carbon dioxide conversion technology has begun. However, more than $90 \%$ of the carbon dioxide is converted to urea and inorganic carbonates; other high-added value of fine chemicals for carbon dioxide reduction is very low. The fundamental reason is because of the thermodynamic stability of carbon dioxide and its kinetic inertia. The way to solve this important issue is to activate carbon dioxide with metal complexes and highly active catalysts. Under this premise, strong methods for converting carbon dioxide into high value-added fine chemicals include the following: 1) Use of high internal energy active reagents such as hydrogen, unsaturated olefins, cyclic unsaturated compounds and organometallic complexes; 2) selecting compounds with high stability as target products, such as organic carbonate compounds; 3 ) removing the specific intermediate compound to shift the chemical reaction equilibrium to the target product; and 4) making full use of natural energy such as light energy. At present, the main carbon dioxide reduction technologies include: thermal 
hydrogenation catalytic reduction, electrochemical reduction, light energy catalytic reduction and hydrothermal reduction.

\subsection{Catalytic hydrogenation.}

Catalytic hydrogenation of carbon dioxide to organic compounds is the most mature technology for the utilization of carbon dioxide [4]. By adding expensive hydrogen source, the hydrogen and carbon dioxide molecules undergo redox reaction on the active surface of the transition metal catalyst under high temperature and pressure conditions to generate high value-added chemical products. The main conversion path and form include the following:

$$
\begin{gathered}
\mathrm{CO}_{2}+\mathrm{H}_{2} \rightarrow \mathrm{CO}+\mathrm{H}_{2} \mathrm{O} \\
\mathrm{CO}+2 \mathrm{H}_{2} \rightarrow-\mathrm{CH}_{2}-+\mathrm{H}_{2} \mathrm{O} \\
\mathrm{CO}_{2}+\mathrm{H}_{2} \rightarrow \mathrm{HCOOH} \\
\mathrm{CO}_{2}+3 \mathrm{H}_{2} \rightarrow \mathrm{CH}_{3} \mathrm{OH}+\mathrm{H}_{2} \mathrm{O} \\
\mathrm{CO}_{2}+4 \mathrm{H}_{2} \rightarrow \mathrm{CH}_{4}+2 \mathrm{H}_{2} \mathrm{O} \\
\mathrm{R}_{2} \mathrm{NH}+\mathrm{CO}_{2}+\mathrm{H}_{2} \rightarrow \mathrm{HCONR}_{2}+\mathrm{H}_{2} \mathrm{O}
\end{gathered}
$$

However, the main reduction products are $\mathrm{C} 1$ compounds such as carbon monoxide, methanol, formic acid, methane and amides. However, this method requires the addition of expensive hydrogen as a reducing agent. Hydrogen, as a stable and easily combustible gas, consumes extra energy during its production, transport and storage. And the use of clean energy as a raw material can lead to energy waste. At the same time, most of the catalysts used in this method are composite catalysts or precious metal catalysts such as $\mathrm{Pd}, \mathrm{Rh}, \mathrm{Ir}$ and $\mathrm{Ru}$, which are also prone to carbon deposition in the gas phase reaction, resulting in poisoning of the catalyst.

\subsection{Electrochemical reduction.}

Electrochemical reduction is one of the effective methods to overcome the high reduction electrochemical potential of $\mathrm{CO}_{2} / \mathrm{CO}_{2}{ }^{-}$. The basic principle is to rely on the energy of the electrode to excite the carbon dioxide through a high transition state to generate $\mathrm{CO}^{*}$ intermediates. The reaction can be carried out at a lower temperature; the reaction process equipment is simple [5].

In addition, the reduction of carbon dioxide is accomplished at the cathode, so catalysis can be achieved by depositing some precious or transitional metal on the surface of the cathode material. However, the products obtained by electrochemical hydrogenation reduction are mainly $\mathrm{C} 1$ compounds. The formation of organic compounds with more than two carbon atoms is difficult or the Faraday efficiency of the products is not high, which is also the main challenge for the current electrochemical reduction of carbon dioxide. And this multi-electron transfer reaction for carbon dioxide reduction, the product selectivity is difficult to control, resulting in the subsequent separation process cumbersome.

\subsection{Photocatalytic reduction.}

Photocatalytic reduction is to make the catalytic semiconductor material absorb light energy to stimulate the generation of photo-generated electrons and photo-generated holes, which directly or indirectly react with carbon dioxide to generate organic compounds, as shown in Fig. 2. Since its birth, photocatalysis has received a great deal of attention and is considered as the main source of all energy in the future. Although its application prospects are not yet clear, but the photoelectric conversion efficiency continue to have new breakthroughs [6].

At present, photocatalysts commonly used in laboratories are mainly $\mathrm{TiO}_{2}$, which has relatively high catalytic activity, strong corrosion resistance, good stability, non-toxicity and relatively low cost. The key problem restricting the practical application of photocatalytic reduction is that its reduction 
efficiency is too low. At the same time, the preparation cost of carbon dioxide photocatalyst is high, and the components are unstable and easily lost to cause pollution.

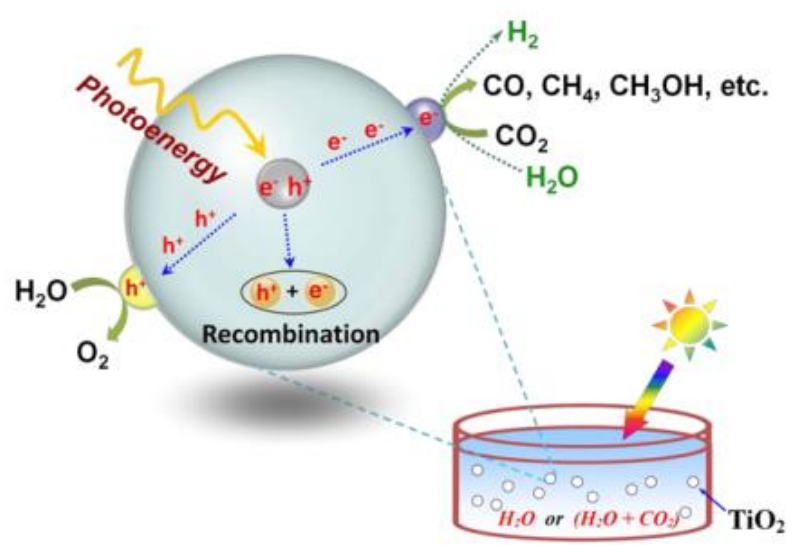

Fig. 2. Photocatalytic principle diagram [6].

\subsection{Hydrothermal reduction.}

Due to its unique advantages, hydrothermal is rapidly becoming one of the hottest technologies in various fields such as chemistry, environment, materials and energy. It is widely used in the synthesis of fine chemicals, especially in the synthesis of porous nanomaterials. Hydrothermal reactions are also used for biodegradable plastics waste disposal, plastic recycling, coal liquefaction and biological waste disposal. Through these practical applications, it can be seen that hydrothermal technology has unique advantages in environmental technology and energy conversion and has great potential and broad practical application prospects. Therefore, combining the resource utilization of carbon dioxide with the unique hydrothermal technology has certainly become a promising research direction and will inevitably lead to a new round of technological changes [7].

\section{Summary}

The combustion of organics and fossil fuel have led to higher greenhouse gas carbon dioxide production and making global warming a pressing issue. Conversion of carbon dioxide into value-added chemicals and fuels seems to be more attractive and promising from the viewpoints of reducing carbon dioxide emission by utilizing it as a feedstock and storing renewable energy in the form of high energy density fuels. It has important scientific and practical significance.

\section{Acknowledgements}

The authors gratefully acknowledge the financial support of the National Natural Science Foundation of China (No. 21277091 \& 51472159), the State Key Program of National Natural Science Foundation of China (No. 21436007) and Key Basic Research Projects of Science and Technology Commission of Shanghai (No. 14JC1403100).

\section{References}

[1] LI Z, DU H L, XIAO Y, et al. Renewable Energy, 2017, 114(11):534-546.

[2] FIGUEROA J D, FOUT T, PLASYNSKI S, et al. International Journal of Greenhouse Gas Control, 2008, 2(1): 9-20.

[3] YAO Z Y, ZHANG D B, YAO P W, et al. Science of the Total Environment, 2017, 607(5):433-442.

[4] WANG W, WANG S, MA X, et al. Chemical Society Reviews, 2011, 40(7): 3703-3727.

[5] QIAO J, LIU Y, HONG F, et al. Chemical Society Reviews, 2014, 43(2): 631-675. 
[6] Ma Y, Wang X, Jia Y, et al. Chemical reviews, 2014, 114(19): 9987-10043.

[7] JIN F, GAO Y, JIN Y, et al. Energy \& Environmental Science, 2011, 4(3): 881-884. 